\section{How to help Russian science}

SIR - Pity for Russian science has become fashionable, as well as fear of the 'new Russians'. But there is also a new class of 'new paupers' in Russia - a large group that includes scientists. The rights of scientists have been betrayed by society, by the government, by those wanting to promote capitalism and by bourgeois interests.

The struggle for survival has become an everyday reality for scientists. Salaries range from the equivalent of US\$30 a month for an MSc to $\$ 100$ a month for a professor, while the cost of living is approaching that elsewhere. Transformation of Russia from a superpower to a developing country also means that the number of scientists may be reduced to only a tenth of what it was.

Russian science is threatened with extinction. Experienced scientists are either emigrating or moving into business in pursuit of higher salaries. Fundamental science has always been one of Russia's strengths but now commercialization is taking over.

Large research institutes belonging to the different academies of science and covering all fields of study are desperately struggling to survive stringent budget cuts. They often occupy huge buildings and have inflexible administrative structures. Hopes even for the money allocated in the 1995 budget are disappearing with every day of war in dissident republics. Many research institutes delay the payment of salaries and scientists wait to be laid off. International programmes, however generous, cannot solve the problems of Russian science and help only to prolong the agony. Newly established foundations such as the Russian Foundation for Fundamental Research cannot support even a limited number of research groups for lack of funds.

Thousands of talented young scientists between the ages of 20 and 30 have joined the 'brain drain' to the West. Older scientists with both theoretical and practical experience continue to work in Russia: they are the people most in need of help.

At national level, I have the following proposals:

- Research centres consisting of active groups with joint scientific programmes should be organized to solve the acute scientific problems.

- An independent trade union should be set up to help scientists to find jobs and to help those already in work to establish contacts with potential customers.

- Laboratory space and equipment should be provided to such research groups.

At an international level:

- Laboratories elsewhere should provide opportunities for active Russian scientists to visit.

- Western scientific organizations and companies could cooperate directly with active Russian groups in certain active areas.

- An organization should be set up to develop science strategies and projects.

- English-speaking universities should be set up in cities such as Moscow and St Petersburg and should employ Russian scientists

\section{R. I. Zhdanov}

Nauchnyi proezd, 8 ,

Moscow 117246, Russia

\section{Popov, Marconi and radio}

SIR - The centenary this year of wireless communication, or radio, brings to mind Professor Alexandr S. Popov (18591906), who together with Heinrich R. Hertz laid the foundation stone of the discovery. Hertz created the source of electromagnetic waves, then called 'hertzian waves'; Popov developed the first receiver of electromagnetic waves. Augusto Righi ${ }^{1}$ wrote: "The new features of Popov's apparatus are the use of an electrically moved hammer or electric bell, to restore the initial resistance of the coherer, and the use of a vertical conductor, called later antenna, for receiving the waves."

The first demonstration of the hertzian wave receiver as 'a lightning detector' took place at the St Petersburg Physical Society on 7 May 1895 (refs 2, 3), and Popov demonstrated the transmission of intelligent signals in March 1896 to an audience of scientists from the society ${ }^{4}$. Popov was at that time teaching at the Russian Navy's Torpedo School in Kronstadt $^{5,6}$, and open publication about the transmission of intelligent signals was restricted by the Navy?

Popov continued to investigate electromagnetic wave propagation and worked on the development of the first wireless communication systems in Russia. But production of wireless telegraphy was apparatus not successful in Russia. On the eve of the Russo-Japanese War of 1904 05, the Russian Navy was forced to use German-made radio equipment $t^{6,7}$.

Popov was a physicist and an electrical engineer with wide interests. In 1901, he became a professor at the St Petersburg Institute of Electrical Engineering, and in 1905 was elected director (rector). In December 1905 he was ordered by governor of St Petersburg to take repressive measures against student political disturbances. He refused. His health was badly
Institute of Biotechnology, affected and he died soon afterwards ${ }^{8}$.

Who could be said to be the inventor of radio, Popov or Marconi? The best answer is given by the historian Mouromtseff: "It is hardly possible to establish with certainty on which particular day either inventor conceived his final idea of wireless communication. Is it, however, necessary? From all evidence it is clear that Russia learned about wireless and obtained it in practical form through the knowledge and ingenuity of the scientist Professor Popov; the Western world unquestionably received all that through the energy and ingenuity of the young Marco$\mathrm{ni}$, and his unabatable faith in the future of radio".

\section{Orest G. Vendik}

Department of Electronics,

Electrotechnical University,

St Petersburg 197376, Russia

1. Righi, A. \& Dessau, B. Die Telegraphy ohne Draht Nieweg Braunschweig, 1907)

2. Popov, A. S. Zh. russk. fiz.-khim. Obshch. (Phys, pt 1) 27. 259-260 (1895)

3. Popov. A. S.Zh. Russk. fiz.-khim. Obshch. (Phys. pt 1) 28, 1-14 (1896).

4. New Encyclopaedia Britannica, Macropaedia, 14, 799 800 (1974).

5. New Encyclopaedia Britannica, Micropaedia, 8, 120 1974)

6üsskind Ch. Proc. I.R. E. 50, 2036-2047 (1962)

7. Golovin, G. I. (ed Klyatskin, I. G.) A. S. Popov isobretatel" radio (Isd. Svyasi i Radio, Moscow, 1945)

8. Dictionary of Scientific Biography Vol. II (ed. Gillispie, C. C.) 93-94 (Scriber, New York, 1981)

9. Mouromtseff, I. E. Proc. I.R.E. 38, 609-611(1950).

\section{Bigger still}

SIR - Henry Miller (Nature 373, 652; 1995 ) is irked that.H. C. Bennett-Clark states in his review of Diatoms to Dinosaurs (Nature 372, 629;1994) that: "Living organisms range in size from a diameter of about one hundredth that of a typical human cell to a length of 30 metres, with weights ranging from the infinitesimal to that of a medium-sized airliner". Miller remarks that: "Perhaps because BennettClark is a zoologist he has overlooked the fact that there is another kingdom of living things called plants, which include the largest of all living things, the sequoia trees of California, estimated to weigh more than 1,000 tons."

Perhaps because Miller is a plant chauvinist he has overlooked yet another kingdom of living things called fungi. A thallus of the fungus Armillaria bulbosa was reported to have spread over some 15 hectares in soil in the forests of North America, is estimated to be more than $10,000 \mathrm{~kg}$ in weight and to be some 1,500 years old (Nature 356, 382 \& 356, 428; 1992)! To keep the facts straight, much of the mass of the sequoia tree is contributed by the dead xylem cells.

\section{Ramesh Maheshwari}

Department of Biochemistry,

Indian Institute of Science,

Bangalore 560120 , India 